\title{
Erratum to: DeepCpG: accurate prediction of single-cell DNA methylation states using deep learning
}

Christof Angermueller ${ }^{1 *}$, Heather J. Lee ${ }^{2,3}$, Wolf Reik ${ }^{2,3}$ and Oliver Stegle ${ }^{1 *}$

\section{Erratum}

After publication of this article [1] it was noticed that the legend of Fig. 3 is incorrect. The circles should be labelled as 'De novo' and triangles as 'Annotated'.

The original article has been updated.

\begin{abstract}
Author details
${ }^{1}$ European Molecular Biology Laboratory, European Bioinformatics Institute, Wellcome Genome Campus, Hinxton, Cambridge CB10 1SD, UK. ${ }^{2}$ Epigenetics Programme, Babraham Institute, Cambridge, UK. ${ }^{3}$ Wellcome Trust Sanger Institute, Wellcome Genome Campus, Hinxton, Cambridge CB10 1SA, UK.
\end{abstract}

Received: 8 May 2017 Accepted: 8 May 2017

Published online: 12 May 2017

\section{Reference}

1. Angermueller C, Lee HJ, Reik W, Stegle O. DeeCpG: accurate prediction of single-cell DNA methylation states using deep learning. Genome Biol. 2017;18:67.

\footnotetext{
*Correspondence: cangermueller@ebi.ac.uk; oliver.stegle@ebi.ac.uk

${ }^{1}$ European Molecular Biology Laboratory, European Bioinformatics Institute,

Wellcome Genome Campus, Hinxton, Cambridge CB10 1SD, UK
} 